\title{
SISTEMAS FISCALES COMPARADOS
}

\author{
Dr. Victor Giudice Baca*
}

\begin{abstract}
RESUMEN
El presente ensayo versa sobre la unidad y diversidad de los sistemas Fiscales del mundo contemporáneo. Se considera que los sistemas fiscales se componen de la Ley Tributaria, la Autoridad Recaudadora, el Tribunal Fiscal, la Policia Fiscal y la vigilancia de los Derechos del Contribuyente por el Tribunal de Derechos Constitucionales. También considera que los sistemas fiscales experimentan un ciclo de vida: La Génesis del Sistema Tributario, el Sistema Tributario Desarrollado y los Sistemas Tributarios Maduros, que muestran un mínimo de impuestos (cinco) y un máximo de eficiencia en las declaraciones voluntarias (98\% de la recaudación).
\end{abstract}

\section{SISTEMAS FISCALES}

Los sistemas fiscales del mundo contemporáneo tienden a uniformarse. La mayoria de está convirtiendo en agencias autónomas del Estado, con un solo objetivo estratégico: lograr el máximo de recaudación por declaraciones voluntarias.

El caso de la Autoridad fiscal Española es que recauda el $98 \%$ por declaración voluntaria y el $2 \%$ por acciones de control (juicios, multas, etc.).

El caso de Alemania (Bundesamt) es muy complicado. Recuerdo haber visto un Manual de declaraciones fiscales, para obreros que tenía ¡más de 800 páginas! Se sabe que los asesores tributarios viven en el Mediterráneo y de allí atienden a sus clientes en las declaraciones. Es importante recordar que un conductor de Buses en Berlîn gana 2000 dólares al mes y debe declarar sus ingresos. Los obreros de la industria pesada (acero, automotriz, química industrial, maquinaria) sobrepasan los 2000 dólares mensuales de salario. Las declaraciones tan complicadas que deben formular las encargan a los consultores financieros (por lo general contadores públicos) localizadoscomo se mencionó, fuera de Alemania.

\section{La Autoridad Fiscal Canadiense} ha pasado por extraordinarios procesos de cambio. El personal es entrenado a portar 40 bases de datos en sus lap-tops, cuando salen por auditorias de campo. En los años recientes los ingenieros de 
sistemas han crecido más rápido que los auditores-contadores. En épocas de conflicto en la recaudación, los abogados crecen más rápido que los ingenieros de sistemas. Se considera que el aumento de ilicito tributario ha renacido en el país, para sorpresa de las autoridades tributarias. Una investigación encargada a consultoras externas encontró una causa sorprendente del aumento inusual de los delitos fiscales: los grupos de blanqueadores de fondos, que habian iniciado negocios legales, traian al mundo tributario las malas costumbres del negocio ilegal de origen: declaraciones falsas, doble facturación, etc.

La Autoridad Fiscal de EE.UU. (IRS) es criticada por la frondosa legislación, que se ha calculado en 36 tomos de dispositivos legales. El Instituto Liberal CATO de California plantea que en EE.UU. debe existir un solo tributo: el IGV. y que todos los demás tributos deben abolirse (sistema fiscal de un solo tributo o "monotributo").

En la actualidad, las personas naturales contribuyen con el $75 \%$ de la recaudación y las empresas sólo con el $10 \%$. Aunque el Gobierno declara que la presión tributaria es sólo el $20 \%$ del PBI, la oposición liberal estima que el presupuesto público más los ingresos propios del Estado trepan al $40 \%$ de presión tributaria.

Estonia, Polonia, Hungria, República Checa y Lituania, ingresarán el primero de mayo del 2004 a la Unión Europea. Deberán adecuar sus sistemas tributarios a la integración europea. En la lista anexa aparecen sus direcciones electrónicas.
El sistema tributario de Japón ofrece grandes experiencias a lo largo del siglo $\mathrm{XX}$.

Hasta 1948, el impuesto al comercio exterior y la tierra eran los principales ingresos del fisco. Luego de la Guerra (1948) se hicieron vigorosos avances en la imposición empresarial. Se introdujo el impuesto a la renta empresarial y premios a los buenos contribuyentes. El impuesto a la Agricultura desapareció y el IGV apenas alcanza al $3.5 \%$ en el pais.

Los sistemas tributarios internacionales nos transportarán a mundos muy singulares. Por ello, el estudio de sistemas fiscales comparados puede aportar nuevas ideas para comprender que los sistemas de recaudación poseen un ciclo de vida: nacen, se desarrollan, maduran y se transforman. En la bibliografia, se proporciona una lista de direcciones electrónicas para la investigación de los sistemas tributarios del mundo.

\section{CONCLUSIONES}

1. El estudio de los sistemas fiscales permite comprender que ellos reflejan el desarrollo económico del país que los origina. Por ello existen sistemas fiscales en formación, sistemas fiscales desarrollados $\mathrm{y}$ sistemas fiscales maduros que están perfeccionando el cumplimiento y la eficiencia.

2. La comparación de los sistemas fiscales nos indica que hay una estandarización (convergencia) de los sistemas en número máximo de tributos; un 
acercamiento a convertir el Impuesto a la Renta como el ingreso fiscal principal (75-80\%) de los sistemas tributarios. Así mismo, la caída de la recaudación aduanera es compensada con el aumento de los ingresos fiscales vía IGV, fenómeno de mayor manifestación en los procesos de integración.

3. Los sistemas fiscales desarrollados (Alemania, EE.UU., Japón) recaudan tan sólo el 3-4\% por aduanas, en tanto que el Impuesto a la Renta de empresas y personas naturales montan al $75-80 \%$ de los ingresos del Estado. En el caso de los EE.UU., los impuestos a la Renta Personal ya son mayores que los impuestos a la Renta Empresarial.

4. Los sistemas fiscales federales (Brasil, Argentina y EE.UU.) pueden proporcionar una ventana al futuro de cómo se formará el sistema fiscal regional. Colombia es el país que ya ha experimentado 12 años de regionalización tributaria.

5. Es conveniente estudiar el sistema tributario regional de Colombia que ya tiene 12 años de experimentación y se han publicado varios informes de evaluación. Se considera que el Gobierno Central se ha quedado con los impuestos mayores y más fáciles de recaudar y ha delegado a los municipios y regiones los impuestos y tasas de menor rendimiento y más caros de recaudar.

6. El sistema tributario de Brasil es federal. El gobierno estimula a los empleados y funcionarios a través de préstamos de vivienda a largo plazo, a fin de asegurar la conducta moral: un descubrimiento de corrupción no sólo lo dejará sin trabajo; también sin casa. Los aumentos de precio de la gasolina; no pueden ir al Gobierno Federal, sino que son recaudados por los municipios. Así se evitan los "Gasolinazos" fiscales.

7. El personal de los sistemas tributarios está ascendiendo en calidad. Los contadores, ingenieros de sistemas y abogados se están convirtiendo en mayoría del personal de autoridades tributarias. La informatización de los servicios (consulta, pagos autorizaciones) así como las bases de datos construidos para el cruce de información conduce a que los programadores e ingenieros de sistemas estén creciendo más rápidamente que los abogados. Al mismo tiempo que aumenta la calidad del Personal, aumenta también la necesidad de pagar sueldos similares al sector privado en las autoridades tributarias.

8. El sistema tributario de Venezuela experimenta dificultades para desarrollarse. Los ingresos fiscales por el monopolio estatal de petróleo han ensombrecido el desarrollo de una cultura tributaria. Al igual que el guano y el salitre en el Perú del siglo XIX (1840-1879) el petróleo de Venezuela constituye el principal ingreso fiscal del Estado. 


\section{BIBLIOGRAFÍA}

CIAT. Sistema Tributario de América Latina. Ver en linea CIAT.

CIAT. Informe de Petit Comité sobre indicadores de eficiencia de las autoridades tributarias (2003 en línea en CIAT).

CIAT. La capacidad contributiva. Ensayos de Congreso del CIAT 2002 (Ver numerosos articulos en línea).

CONGRESO DE CONTADORES. Uruguay, 2001. Ver Sistemas Fiscales de América Latina y la Integración.
GUIPUCAMAYOC. Revista del Instituto de Investigaciones de la Facultad de Ciencias Contables de la Universidad Nacional Mayor de San Marcos.

SUNAT. El Gasto Fiscal. Un Estudio de los Costos de los convenios de estabilidad Lima, 2003.

SUNAT. La autoridad tributaria del Canadá. Edición y traducción de SUNAT2002. 